\title{
Dioxin contamination and poisoning
}

Background and epidemiology: Sporadic cases of acute dioxin poisoning with an unknown source of exposure, such as that experienced by Ukrainian President Viktor Yushchenko, are extremely rare. Most of the public health lessons learned about dioxin toxicity over the past century have arisen from relatively obvious accidental occupational exposures or chemical catastrophes. From these events and related toxicologic investigations, sobering health implications of long-term, low-level exposure to this ubiquitous environmental contaminant have been extrapolated and environmental protection interventions, such as reductions in municipal waste incineration, activated.

Dioxins constitute a group of chlorinated dibenzo-p-dioxin and dibenzofuran congeners that are largely the by-product of incineration processes and the production of chloroorganic chemicals such as those found in some wood preservatives and herbicides. Dioxin and related compounds (furands and polychlorinated biphenyls) are lipophilic and persist in the food chain. Ingestion is the most common route of exposure in humans, with foods such as cow's milk, beef fat, hen's eggs and fish. High lipid solubility leads to lifelong accumulation in humans. The half-life of certain dioxins in humans has been estimated to be 7 years.

Once injested, dioxin congeners bind to the aryl hydrocarbon receptor (AhR), a nuclear receptor and transcription factor. The relative toxicity of different dioxins varies by their binding affinity to AhR. Binding induces or suppresses the transcription of numerous genes and triggers molecular mechanisms that are associated with cancer development. ${ }^{2}$

The public health disasters that alerted us to the hazardous potential of these compounds include the Yusho and $\mathrm{Yu}$ Cheng incidents in Japan (1968) and Taiwan (1979) respectively, in which the consumption of contaminated rice oil resulted in severe acute and chronic poisonings; the 1976 explosion in a chemical plant in Seveso, Italy, that released a dioxin cloud in a densely populated area; and, more recently, the 1999 incident in Belgium in which contaminated chicken feed resulted in Europeans ingesting chickens and eggs that had dioxin levels exceeding tolerable limits by up to 250 -fold. From these exposures, we have learned that the signs of acute dioxin poisoning (i.e., total body burden $>8500 \mathrm{ng}$ ) include chloracne, elevated liver enzyme levels, pulmonary deficiency and neurologic deficits (sensory changes, headaches, malaise). Long-term epidemiologic follow-up of cohorts with acute and chronic exposure have revealed excesses of several specific cancers as well as genderspecific effects, such as an excess of diabetes among exposed women and a lower male:female ratio among the offspring of exposed men. ${ }^{3}$ In 1997 the International Agency for Research on Cancer classified TCDD as a group 1 carcinogen.

Clinical management: It is highly unlikely that a primary care physician will be faced with a patient who has acute dioxin poisoning. In such a situation, consultation with a toxicologist, public health official and the laboratory for advice on investigation and management is recommended. Of greater importance is communicating accurate information to patients about the risks of dioxin in the food chain and the environment.

Prevention: Dioxin levels in certain foods (e.g., fish) are rou- tinely and randomly monitored. Tolerable daily intakes have been set, and estimates of hu-

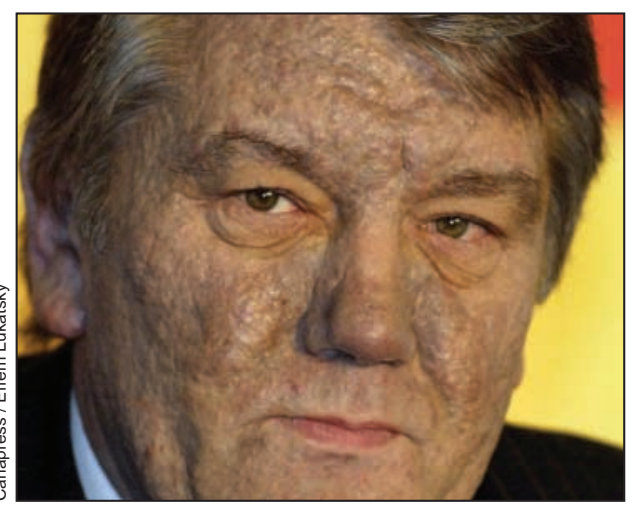

man dietary intake and daily dose uptake have been determined. ${ }^{4}$ There have been no reports of acute toxic responses or chronic toxic effects ${ }^{1}$ in humans who eat normal diets (i.e., moderate intake of a variety of foods) that are generating background dioxin body burdens. Patients should be encouraged to follow a balanced diet, such as that laid out in Canada's food guide, and to support environmental and industrial hygiene interventions that reduce the emission of dioxins.

\section{Erica Weir}

CMAF

\section{References}

1. Parzefall W. Risk assessment of dioxin contamination in human food. Food Chem Toxicol 2002;40:1185-9.

2. Steenland K, Bertazzi P, Baccarelli A, Kogevinas M. Dioxin revisited: developments since the 1997 IARC classification of dioxin as a human carcinogen. Environ Health Perspect 2004;112 (13):1265-8

3. Pesatori AC, Consonni D, Bachetti S, Zocchetti C, Bonzini M, Baccarelli A et al. Short and long-term morbidity and mortality in the population exposed to dioxin after the 'Seveso accident.' Industrial Health 2003;41: 127-38.

4. Great Lake Health Effects Program, Public Health Branch. The bealth and environment bandbook for bealth professionals. Ottawa: Health Canada and Ontario Ministry of Health and Longterm Care; 1997. Available: http://dsppsd.pwgsc.gc.ca/Collection/H46-2-98211E-4.pdf (accessed 2005 Feb 9). 